\title{
Maintenance of certification for radiologists: an overview of European countries
}

\author{
Robert M. Kwee ${ }^{1}$ and Thomas C. Kwee $2^{2^{*}}$
}

\begin{abstract}
Background: It is currently unclear whether the continuing medical education (CME) requirements for radiologists to keep up their certification are equal across Europe, which would be desirable for uniform cross-border quality of radiology and because of the fundamental principle of free movement of workers in the European Union. This study aimed to determine the maintenance of certification requirements for radiologists in different European countries.
\end{abstract}

Methods: National radiological societies of European countries and/or their delegates as listed on the European Society of Radiology website were contacted to inquire about the maintenance of licensure requirements for radiologists in their country. Data were analysed using descriptive statistics.

Results: Forty-six European countries were contacted. Response rate was 80\%. Twenty-two of 36 responding countries (59\%) reported mandatory requirements to maintain a radiologist's license to practise. The median license period was 5 years (range 1-7). The median required number of CME points per year was 40 (range 8-58, interquartile range 30). Eight countries reported additional requirements, including practising clinical radiology, attending quality meeting/clinical audit, and attending additional courses (such as radiation safety training and advanced medical training course). Fifteen of 37 responding countries (41\%) did not report mandatory requirements.

Conclusions: There is considerable heterogeneity across European countries regarding the maintenance of certification requirements for radiologists. More homogeneity is desired for uniform quality assurance and professional mobility of radiologists across Europe. The data from our overview may be used to establish a benchmark for national societies who issue maintenance of licensure requirements for radiologists.

Keywords: Licensure, Education, Continuing, Certification, Radiology

\footnotetext{
* Correspondence: thomaskwee@gmail.com

${ }^{2}$ Department of Radiology, Medical Imaging Center, University Medical Center Groningen, University of Groningen, Hanzeplein 1, P.O. Box 30.001, 9700 RB Groningen, The Netherlands

Full list of author information is available at the end of the article
}

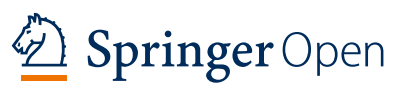

(c) The Author(s). 2020 Open Access This article is licensed under a Creative Commons Attribution 4.0 International License, which permits use, sharing, adaptation, distribution and reproduction in any medium or format, as long as you give appropriate credit to the original author(s) and the source, provide a link to the Creative Commons licence, and indicate if changes were made. The images or other third party material in this article are included in the article's Creative Commons licence, unless indicated otherwise in a credit line to the material. If material is not included in the article's Creative Commons licence and your intended use is not permitted by statutory regulation or exceeds the permitted use, you will need to obtain permission directly from the copyright holder. To view a copy of this licence, visit http://creativecommons.org/licenses/by/4.0/. 


\section{Key points}

- Fifty-nine percent of European countries have mandatory requirements to maintain a radiologist's license to practise.

- In these European countries, radiologists are required to obtain at least 8 up to 58 (median 40) CME credits per year.

- Standardisation of maintenance of certification requirements is desired for more uniform quality and interchangeability of radiologists across Europe.

\section{Introduction}

Radiologists have to undergo intensive training and assessment in order to get accredited by pertinent governing bodies [1]. In Europe, radiology training takes on average 5 years (range 2-6 years), whereas subspecialty fellowship training is offered in just over half of European countries [1]. The ESR has defined the training requirements for trainees in radiology [2]. In 2011, the European Society of Radiology (ESR) created the European Diploma in Radiology (EDiR), which serves the standardisation and accreditation of radiologists across European borders [3, 4]. From the times of Hippocrates, medical doctors have taken oaths to keep their knowledge and skills up-to-date [5]. The importance of keeping up with knowledge and new developments is selfevident to maintain an adequate level of patient care. As progress in medicine becomes ever faster, the necessity to update ones knowledge is even greater [5]. This especially holds true for radiology, where new knowledge is being developed at an increasingly rapid rate owing to technological advances $[6,7]$. The process of continuing medical education (CME) is a part of every physician's professional growth, development, and lifelong learning $[8,9]$. It aids the radiologist in keeping current with new techniques, procedures, and information [8]. To our knowledge, however, it is not clear yet whether the CME requirements for radiologists to keep up their certification are equal across Europe. Equal CME requirements would be desirable for uniform cross-border quality of radiology and because of the fundamental principle of free movement of workers in the European Union (EU) [10]. Therefore, the purpose of our study was to determine the maintenance of certification requirements for radiologists in different European countries.

\section{Methods}

Ethics committee approval was not applicable for this study. This study was driven by personal interest and not an ESR initiative. The authors who analysed and interpreted the data (R.M.K. and T.C.K.) had no conflicts of interest with regard to this study.

\section{Data collection and analysis}

National radiological societies of European countries and/or their delegates as listed on the ESR website [11] were contacted by email and asked the following single question: "What are the requirements for a radiologist to keep his/her license to practise in your country (e.g. required continuing medical education [CME] points per which time period, minimum number of working hours, etc.)?" Although some countries are geographically not located in Europe but in Asia, they are all ESR member societies and tend to join the ESR activities. These countries were also included under the umbrella of "Europe at large." Emails were initially sent out mid-January 2020. In case of no initial response, repeated emails were sent up to two times within 1 month. In our analyses, 1 $h$ of reportedly required educational activity was regarded to correspond to $1 \mathrm{CME}$ credit [12]. Data were analysed using descriptive statistics.

\section{Results}

Forty-six European countries were contacted. Contact email addresses of Kyrgyzstan and Moldova were not available. Responses were received from 37/46 national radiological societies of European countries (80\% response rate) (Fig. 1), which were included in the analyses. An overview of the responses is displayed in Table 1. Twentytwo of 37 responding countries (59\%) reported mandatory requirements to maintain a radiologist's license to practise. Accordingly, 15 of 37 responding countries (41\%) did not report mandatory requirements. The median license period was 5 years (range 1-7). The median required number of CME points per year was 40 (range 8-57.6, interquartile range 30). Eight countries reported additional requirements, including practising clinical radiology, attending quality meeting/clinical audit, and attending additional courses (such as radiation safety training and advanced medical training course) (Table 1).

\section{Discussion}

Our overview shows that there is a wide variation with respect to requirements to maintain a radiologist's license to practise: in 22 of 37 responding European countries, radiologists are required to obtain at least 8 up to 50 (median 40) CME credits per year, whereas in other European countries, radiologists currently keep their license for life without any mandatory CME requirements. Remarkably, such a considerable heterogeneity with regard to certification maintenance has also been reported for other medical specialties [13-16].

In 2006, Bresolin et al. [17] conducted a survey on maintenance of certification in radiology among 34 countries worldwide [17]. At that time, CME was requested for radiologists in 13 of 24 responding countries (54\%) and requested under certain circumstances in 


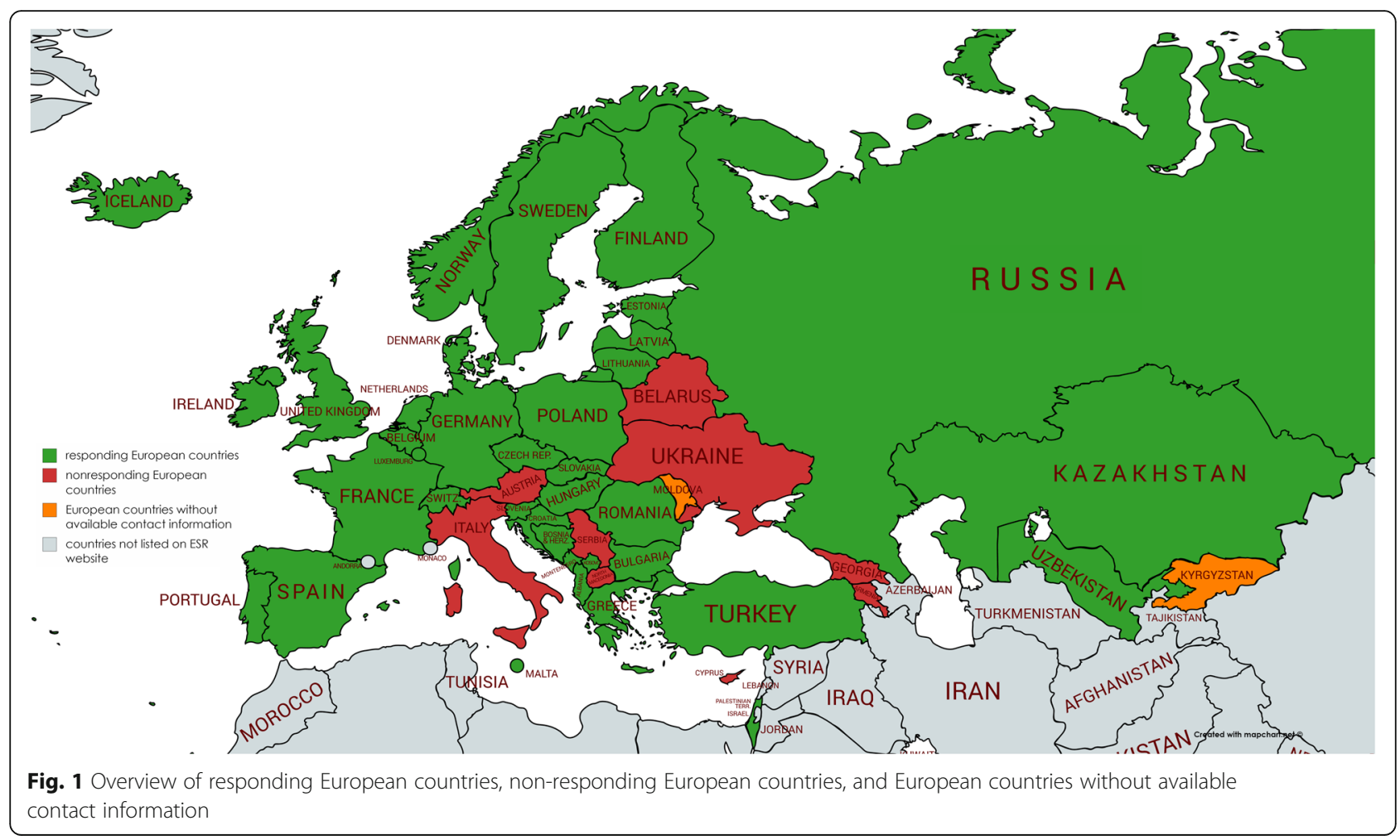

another four countries (17\%) [17]. Interestingly, one third of countries failure to meet the requested CME requirements would not lead to loss of licensure or certification [17]. It should be noted, though, that there is still no evidence of a causative link between improved health care outcomes and either mandatory or voluntary recertification systems [15]. It is difficult to compare the study by Bresolin et al. [17] to our current study, because Bresolin et al. [17] did not report how many CME credits were required per country and because they included responses of only 7 European countries (Austria, Belgium, Germany, Ireland, Romania, Spain, and the UK) [17]. Nevertheless, our study shows that Belgium, Germany, Ireland, and the UK currently have mandatory requirements (minimum number CME credits to be obtained and/or participation in quality improvement types of programs). This suggests a trend towards an increased number of European countries with official requirements to maintain a radiologist's license to practise. Accordingly, some Scandinavian countries also responded that they are planning to formalise CME requirements.

Europe can be compared to the USA in terms of size: both consist of multiple countries (Europe) or states (USA). However, the requirements for maintenance of certification for radiologists in the United States of America (USA) are more uniform than among European countries. Although every state medical board has slightly different CME requirements [18], the umbrella organisation for radiologists in the USA, the American
Board of Radiology (ABR), requires radiologists to attain 75 CME credits every 3 years to satisfy maintenance of certification. At least 25 of these $75 \mathrm{CME}$ credits must be from self-assessment CME activities, which are primarily podium presentations with a post-session assessment instrument [19]. In addition, besides having a valid and unrestricted licensure in all states, radiologists should pass the ABR's online longitudinal assessment and complete at least one practice quality improvement project or participatory quality improvement activity every 3 years [19]. All the provinces in Canada have equal CME requirements for radiologists [20], which is also the case in Oceania [21]. More uniformity in Europe would be desirable for uniform radiology quality and professional mobility of radiologists across European countries. However, the current systems of licensing and registration of medical doctors within the $\mathrm{EU}$, which are controlled by national regulatory bodies, are diverse and complex [13-16]. The ESR could, similar to the EDiR initiative $[3,4]$, play a future leading role to achieve uniformity in maintenance of certification for radiologists across Europe.

Our study has some potential limitations. First, we did not receive a response from all countries. However, the response rate of $80 \%$ can be considered high $[22,23]$. Moreover, even a $100 \%$ response rate would not change the main result. Second, our study presents a current overview of national regulations, which may change in the near future. Third, 8 European countries reported 


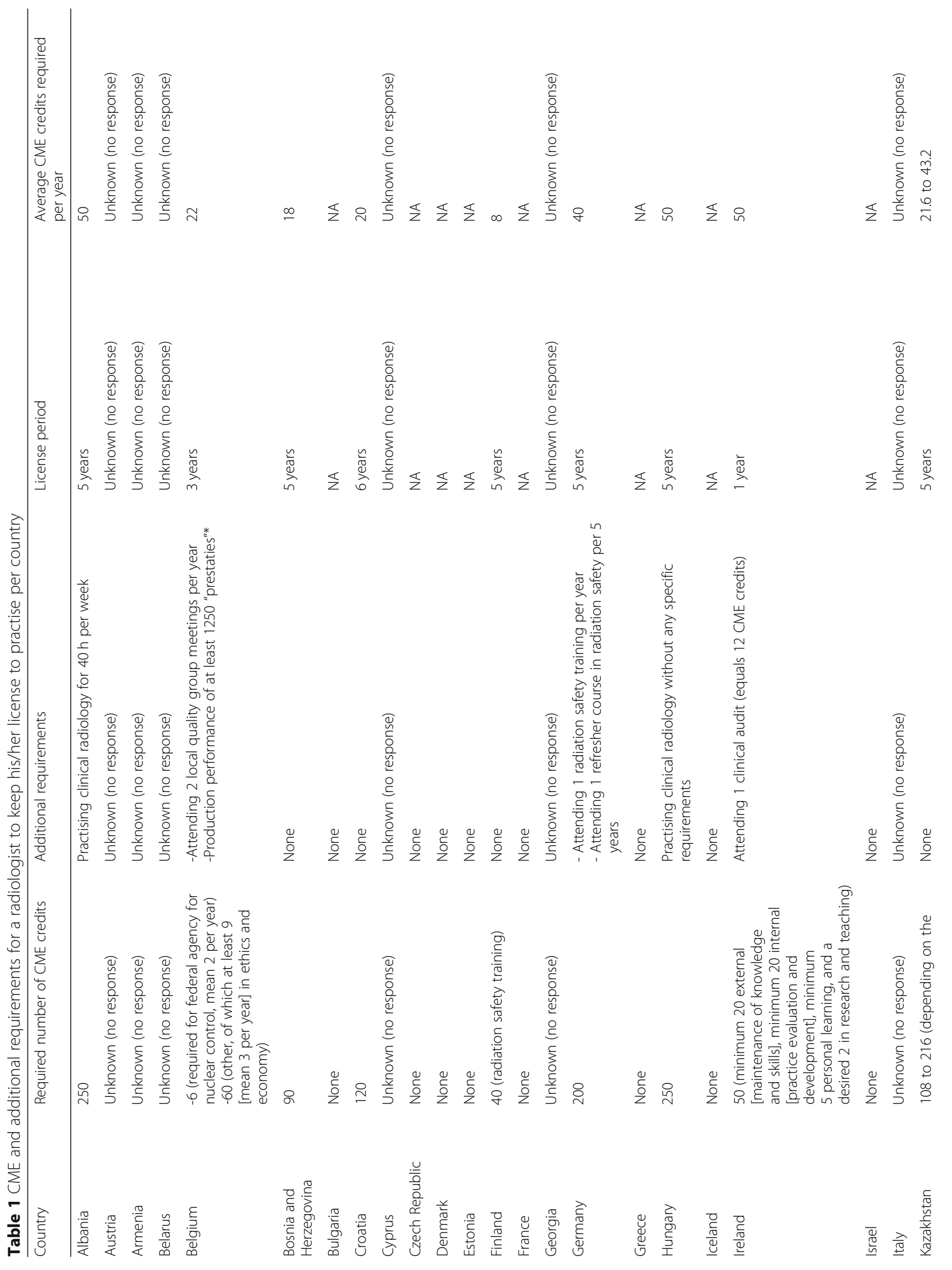




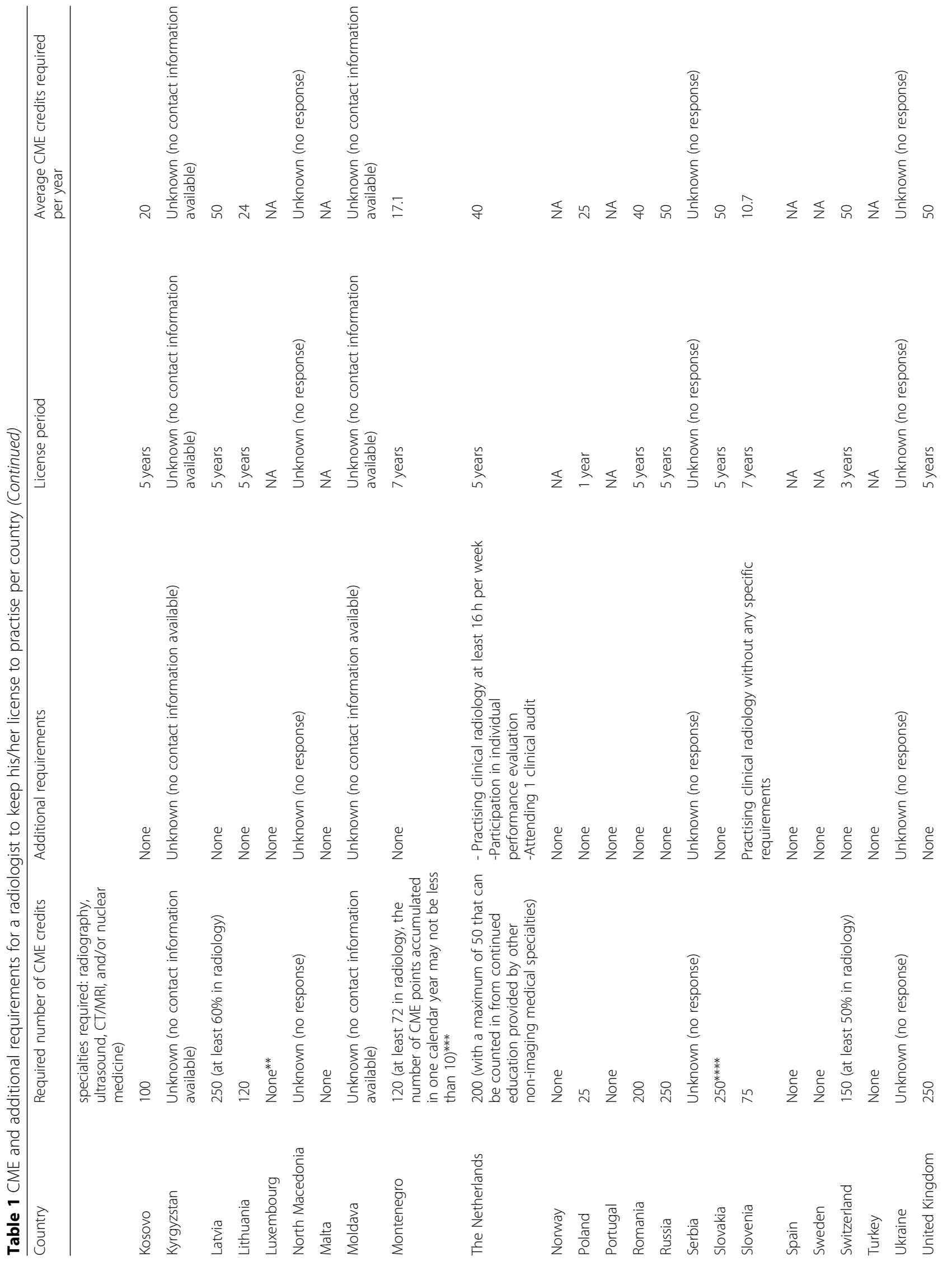




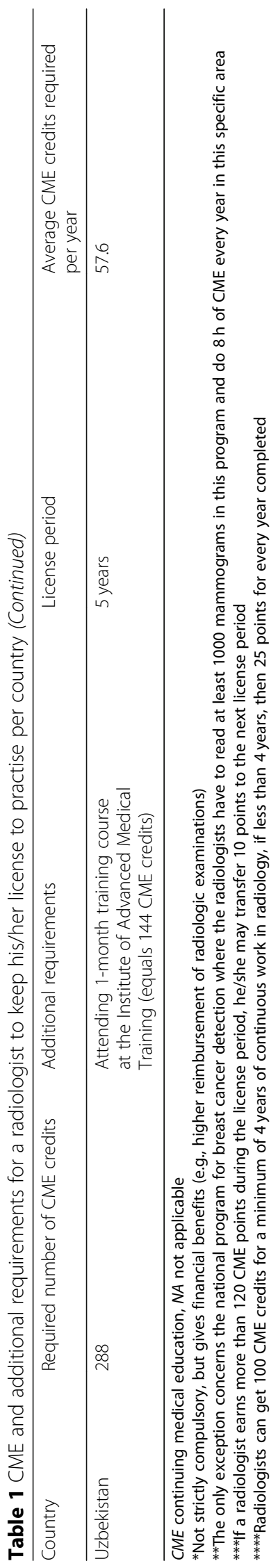


additional requirements besides CME, including practicing clinical radiology, attending quality meeting/clinical audit, and attending additional courses (such as radiation safety training and advanced medical training course), as listed in Table 1. However, it was not possible to provide comparable summary measures of these additional non-CME requirements because of their heterogeneous nature. Nevertheless, they should be taken into account when comparing maintenance of certification requirements among different countries.

In conclusion, our overview shows that there is considerable heterogeneity across European countries regarding the maintenance of certification requirements for radiologists. More homogeneity is desired for uniform quality assurance and professional mobility of radiologists across Europe. The data from our overview may be used to establish a benchmark for national societies who issue maintenance of licensure requirements for radiologists.

\section{Abbreviations}

CME: Continuing medical education; EDiR: European Diploma in Radiology; ESR: European Society of Radiology; EU: European Union

\section{Acknowledgements}

We thank all national radiological societies of European countries and/or delegates for their cooperation.

\section{Authors' contributions}

Both authors contributed to the preparation of the manuscript. Both authors read and approved the final manuscript.

\section{Funding}

None.

\section{Availability of data and materials}

Available on request.

\section{Ethics approval and consent to participate}

Not applicable.

\section{Consent for publication}

Consent for publication was obtained.

\section{Competing interests}

None.

\section{Author details}

'Department of Radiology, Zuyderland Medical Center, Heerlen/Sittard/ Geleen, The Netherlands. ${ }^{2}$ Department of Radiology, Medical Imaging Center, University Medical Center Groningen, University of Groningen, Hanzeplein 1, P.O. Box 30.001, 9700 RB Groningen, The Netherlands.

Received: 29 May 2020 Accepted: 2 July 2020

Published online: 17 July 2020

\section{References}

1. Rehani B, Zhang YC, Rehani MM et al (2017) Radiology education in Europe: analysis of results from 22 European countries. World J Radiol 9:55-62

2. European Society of Radiology. Revised European Training Curriculum for Radiology. Available via https://www.myesr.org/sites/default/files/ESR_2016_ ESR-EuropeanTrainingCurriculum_LEVEL_I\%2BII_Edition_March_2016.pdf Accessed 14 Jun 2020
3. European Board of Radiology (EBR) (2018) The European Diploma in Radiology (EDiR): investing in the future of the new generations of radiologists. Insights Imaging 6:905-909

4. European Board of Radiology. Available via https://www.myebr.org Accessed 10 Mar 2020

5. European Union of Medical Specialists. Areas of expertise. CME - CPD. Continuing Medical Education \& Professional Development. Available via https://www.uems.eu/areas-of-expertise/cme-cpd Accessed 10 Mar 2020

6. European Society of Radiology 2009 (2010) The future role of radiology in healthcare. Insights Imaging 1:2-11

7. Hong SJ, Yoon DY, Lim KJ et al (2019) Radiological clinical practice guidelines published in the last decade: a bibliometric analysis. J Belg Soc Radiol 103:37

8. Steeves LC (1965) The need for continuing medical education. Can Med Assoc J 92:758-761

9. Davis LP, Olkin A, Donaldson SS (2005) Continuing medical education in radiology: a glimpse of the present and of what lies ahead. J Am Coll Radiol 2:338-343

10. European Commission. Employment, Social Affairs \& Inclusion. Working in another EU country. Free movement - EU nationals. Available via https:/ec. europa.eu/social/main.jsp?catld=457 Accessed 10 Mar 2020

11. European Society of Radiology. Institutional Member Societies. Available via https://www.myesr.org/about/organisation/institutional-member-societies Accessed 10 Mar 2020

12. European Society of Radiology. Publications \& Media. CME/CPD guidelines. Available via https://www.myesr.org/sites/default/files/ESR_brochure_03_0. pdf Accessed 10 Mar 2020

13. Solé M, Panteli D, Risso-Gill I et al (2014) How do medical doctors in the European Union demonstrate that they continue to meet criteria for registration and licencing? Clin Med (Lond) 14:633-639

14. Kovacs E, Schmidt AE, Szocska G, Busse R, McKee M, Legido-Quigley H (2014) Licensing procedures and registration of medical doctors in the European Union. Clin Med (Lond) 14:229-238

15. Sehlbach C, Balzan M, Bennett J, Prior Filipe $H$, Thinggaard E, Smeenk F (2018) "Certified ... now what?" On the challenges of lifelong learning: report from an AMEE 2017 symposium. J Eur CME 7:1428025

16. Sehlbach C, Govaerts MJ, Mitchell S, Rohde GGU, Smeenk FWJM, Driessen EW (2018) Doctors on the move: a European case study on the key characteristics of national recertification systems. BMJ Open 8:e019963

17. Bresolin L, McLoud TC, Becker GJ, Kwakwa F (2008) Education techniques for lifelong learning: international variations in initial certification and maintenance of certification in radiology: a multinational survey. Radiographics 28:13-20

18. BoardVitals. Continuing medical education: CME state requirements. Available via https://www.boardvitals.com/blog/cme-requirements-by-state Accessed 10 Mar 2020

19. American Board of Radiology. Maintenance of Certification for Diagnostic Radiology. Available via https://www.theabr.org/diagnostic-radiology/ maintenance-of-certification Accessed 10 Mar 2020

20. Royal College of Physicians and Surgeons of Canada. The Maintenance of Certification Programhttp://www.royalcollege.ca/rcsite/cpd/maintenance-ofcertification-program-e Accessed 14 Jun 2020

21. The Royal Australian and New Zealand College of Radiologists. Clinical Radiology CPD Handbook 2019-2021. https://www.ranzcr.com/fellows/ general/cpd-overview Accessed 14 Jun 2020

22. Cho Yl, Johnson TP, Vangeest JB (2013) Enhancing surveys of health care professionals: a meta-analysis of techniques to improve response. Eval Health Prof 36:382-407

23. Dykema J, Jones NR, Piché T, Stevenson J (2013) Surveying clinicians by web: current issues in design and administration. Eval Health Prof 36:352382

\section{Publisher's Note}

Springer Nature remains neutral with regard to jurisdictional claims in published maps and institutional affiliations. 